\title{
Orman yangınları açısından riskli yılların güneş leke döngüsüne bağlı olarak önceden tahmin edilebilmesi
}

\author{
Uğur BALTACI (Orcid: 0000-0001-8379-7040) ${ }^{1 *}$, Feriha YILDIRIM (Orcid: 0000-0003-4938-3922)² \\ ${ }^{1}$ Orman Genel Müdürlüğü, Orman Yangınlarıyla Mücadele Dairesi Başkanlığı, ANKARA \\ ${ }^{2}$ Gazi Üniversitesi, Fen Bilimleri Enstitüsü, ANKARA
}

*Sorumlu yazar/Corresponding author: ubaltaci@gmail.com, Geliş Tarihi/Recived: 15.09.2017, Kabul Tarihi /Accepted: 21.11 .2017

\begin{abstract}
$\ddot{\mathbf{O z}}$
Ülkemizde ve dünya genelinde, bazı yıllar daha çok sayıda ve büyük ölçekte orman yangınları görülmekte iken, bazı yıllarda orman yangını sayısı ve büyüklüğü azalmaktadır. Orman yangını istatistikleri yangın adedi ve yanan alan olarak zamana bağlı grafik haline dönüştürüldüğünde, minimum ve maksimum noktaları farklı sinüzoidal eğriler şeklinde periyodik bir dalgalanma görülmektedir. Bu durum, orman yangınlarının bir dış etkene bağlı olarak artıp azaldığını gösterebilir. Bu çalışmamızda; adet ve alan olarak orman yangınları ile Güneş Leke Döngüsü (Güneş Radyasyon Döngüsü) karşılaştırılmış ve aralarında güçlü bir ilişkinin olduğu bulunmuştur. Çalışma sonucunda elde edilen bulgular, orman yangını açısından riski yüksek yılların tahmininde kullanılabilecektir. Orman yangınları ile mücadelede orta ve uzun vadeli programlar yapılırken bu tespitlerin göz önünde bulundurulmasının büyük önem arz ettiği düşünülmektedir. Özellikle bütçe planlamaları ve önceden alınacak tedbirler açısından bu öngörülerin dikkate alınmasi uygun olacaktır.
\end{abstract}

Anahtar Kelimeler: Orman yangınları, güneş leke döngüsü, risk tahmini

\section{Forecasting risky years for forest fires depending on sunspot cycle}

\begin{abstract}
Forest fires are observed in larger scales and more frequently in some years in Turkey and across the world, while some years number of fires and affected areas decreased significantly. When the forest fire statistics are visualized by plotting the number of fires and the total burned area by years, a periodic fluctuation in the form of sinusoidal curves, with different minimum and maximum points are observed. This indicates that the forest fires increase or decrease in number due to an external factor that shows periodic behavior. In this study; it has been revealed that there is a strong relationship between forest fires and the Sunspot Cycle (Solar Radiation Cycle). Findings obtained as a result of this study, can be used to predict the high risk years forest fires. It is thought that it is very important to consider these determinations when medium and long-term programs are conducted for forest fire fighting. It will be appropriate to take these precautions into consideration especially in terms of budget planning and precautionary measures to be taken.
\end{abstract}

Keywords: Forest fires, sun spot cycle, risk forecasting

To cite this article (Atıf): Baltacı, U , Yıldırım, F . (2017). Orman yangınları açısından riskli yılların güneș leke döngüsüne bağlı olarak önceden tahmin edilebilmesi. Ormancılık Araştırma Dergisi, 4 (2), 133-142.

DOI: http:/dx.doi.org/10.17568/ogmoad.338404

\section{Giriș}

Orman yangınları sadece yakıp yok ederek değil, erozyonu artırarak, atmosferdeki karbon emisyonunu yükselterek ve madde döngüsünü bozarak ekosistemleri şiddetle etkilemektedir (Gomes ve Radovanovic, 2008).

1937-2016 y1lları arasındaki 80 y1l boyunca ülkemizde toplam 104.276 adet orman yangını çıkmış ve bu yangınlarda 1.662.033 hektar orman alanı zarar görmüştür. Bu bilgilere göre ülkemiz- de yıllık ortalama 1303 adet orman yangını çıkmış ve yılda ortalama 20.775 hektar orman alanı zarar görmüştür. Son 10 yıllık dönemde (2007-2016) ise toplam 24.264 adet orman yangınında 90.424 hektar orman alanı zarar görmüş olup yıllık ortalama yangın adedi 2.426, yıllık yanan alan ise 9.042,4 hektar olarak gerçekleşmiştir. Son 10 yıllık dönemde yangın başına ortalama 3,7 ha orman alanı zarar görmüştür (OGM, 2017).

Orman yangın istatistikleri, 1937 yılından günümüze kadar, yıllık yangın adedi ve zarar gö- 
ren alan olarak analiz edildiğinde; farklı minimum ve maksimum noktalarına sahip periyodik iniş ve çıkışlar olduğu görülmektedir. Orman Genel Müdürlüğ̈̈nün (OGM) orman yangınları ile mücadele kapasitesi yıllar içerisinde büyük bir hızla geliştiğinden, orman yangınları sayıca artmış olsa da erken ve etkili müdahalenin bir sonucu olarak yanan alan sürekli olarak azalmıştır. Ancak yangın adedi ve yanan alan verilerindeki inişli çıkışlı durum değişmemiş, periyodik olarak artışlar ve düşüşler gerçekleşmeye devam etmiştir. Veriler grafik haline dönüştürülüp incelendiğinde, ortalama 4-6 yılda bir orman yangınları açısından riskli dönem yaşandığ 1 görülmüştür (Şekil 1-2).

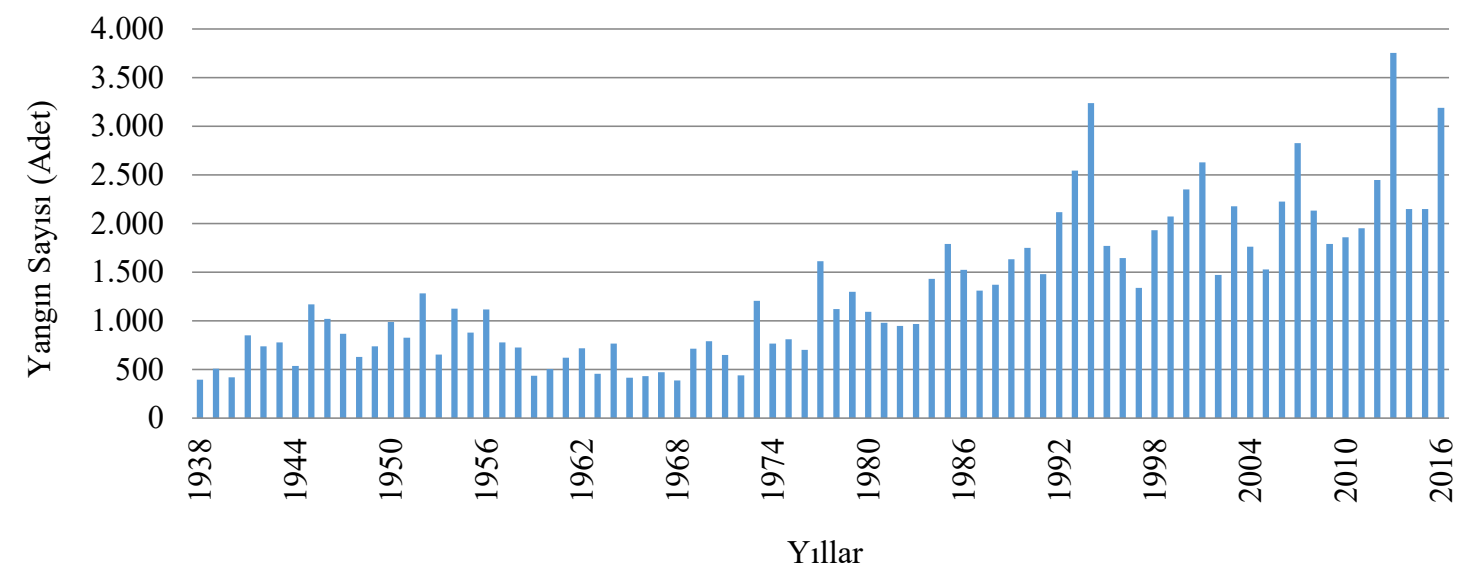

Şekil 1. 1937-2016 yılları arasında çıkan orman yangınlarının yıllara dağılımı (OGM, 2017)

Figure 1. Annual number of forest fires between 1937-2016

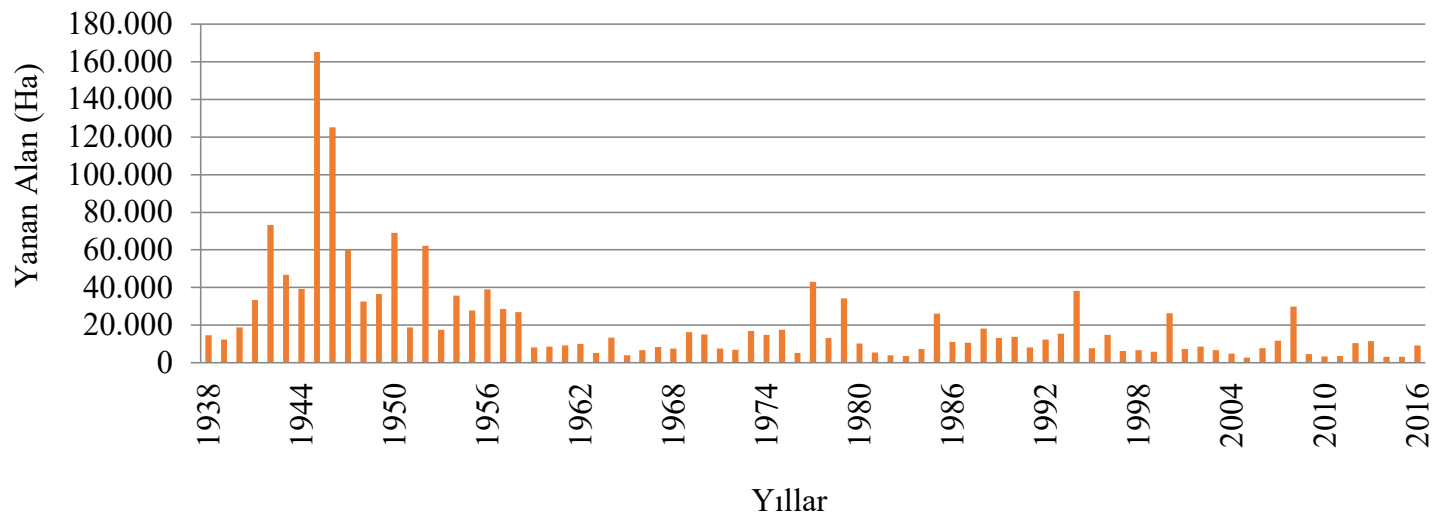

Şekil 2. 1937-206 yılları arasında çıkan orman yangınlarının yıllara göre alan olarak dağılımı (OGM, 2017).

Figure 2. Annual burned areas between 1937-2016

Orman içerisinde ya da yakınında yakılan bir ateşin orman yangınına dönüşmesi ve başlayan yang1nın şiddeti çeşitli kriterlere bağlıdır. Bu kriterlerin başında iklim parametreleri, topoğrafya, yanıcı maddenin çeşidi ve nemi gelmektedir (Sağlam ve ark., 2008). Yanıcı maddenin ince, neminin düşük olması tutuşmayı kolaylaştıracağından orman yangını riskini ve yayılma hızını artırmaktadır (Küçük ve ark, 2008). Eğim arttıkça yangının yayılma hızı da artmaktadır (Zhou ve ark, 2007). Orman yangınları için en tehlikeli şartları ise "şiddetli rüzgar, yüksek eğim ve ince yanıcı maddelerin" bir arada olduğu durum oluşturmaktadır (Aguado ve ark, 2002). Orman yangınının yayılma oran1, yakıt tüketimi ve yangın şiddeti; yakıt özelliklerine ve hava koşullarına bağlıdır (Küçük ve ark., 2007). Ormancılık faaliyetleri de yakıt özellikleri üzerinde etkili olmaktadır (Bilgili, 2003).

İklim parametreleri içerisinde ise rüzgâr, yang1nın başlaması ve yangın şiddeti açısından tüm bu kriterlerden çok daha etkilidir (Küçük ve ark, 2007). Rüzgâr, alçak basınçla yüksek basınç arasında yer değiştiren hava akımı olup hava daima yüksek basınç alanından alçak basınç alanına doğru hareket eder. İki bölge arasındaki basınç farkı ne kadar büyük olursa, hava akım hızı da o kadar fazla olur. Eğer hava kütlesi içerisindeki sıcaklık dağılımı düzgün değilse ya da diğer bir deyişle s1caklık farkları fazla ise kararsız hava koşulları or- 
taya çıkmaktadır (Flannigan ve ark, 2001). Kararsız hava hallerinin ani basınç değişikliği nedeniyle ortaya çıkardığı ani rüzgârlar (gust), orman yang1nın başlaması (ateşin orman yangınına dönüşmesi) ve yayılması (yangın hızı ve şiddeti) açısından en önemli etken olarak görülmektedir (Cramer, 2004).

Büyük orman yangınlarının karakteristik özellikleri; kararsız hava koşulları nedeniyle çok kısa zamanda çok büyük alanlara yayılmaları, şiddetli rüzgar nedeniyle kontrol altına alınamamaları ve bunun sonucunda ancak göl, deniz, orman içi büyük açıklıklar ve ormansız alanlar gibi doğal engellere ulaştığında (yani yanıcı madde bittiğinde) sonlanmalarıdır. Kısaca kararsız hava koşullarının mevcudiyeti güçlü ve ani rüzgarlara sebep olmakta, bu da ormandaki bir ateşin kontrol edilemez büyüklükte afete dönüşmesine yol açmaktadır (Rollo, 2004).

İklim parametrelerini şekillendiren en önemli faktör, gezegenimizin enerji kaynağ 1 olan güneşten gelen radyasyondur. Gezegenimize ulaşan güneş radyasyonundaki değişimler; kısa, orta ve uzun vadeli meteorolojik değişkenleri etkilemektedir. Özellikle güneş radyasyonunun gezegenimize en düşük ve en yüksek miktarda ulaştığı dönemler, atmosferik kararsızlık açısından önemli zaman dilimleridir. $\mathrm{Bu}$ dönemlerde fırtınalar gibi ekstrem hava olayları daha sık görülmektedir. $\mathrm{Bu}$ ekstrem meteorolojik faktörlerin, büyük orman yangınlarını tetikleyen en önemli etken olduğu düşünülmektedir.

\section{Materyal ve Yöntem}

Bu konuda yapılan ender çalışmalardan birinde; Gomes ve Radovanovic İspanya ve Portekiz'de 2005 yılında çıkan orman yangınları ile günes aktivite değișimini karşılaştırmış ve doğrusal bir ilişkinin olduğunu tespit etmişlerdir (Gomes ve Radovanovic, 2008). Yapılan çalışma, güneş aktivitesindeki kısa dönemli değişimlerin sıcaklık üzerindeki etkisine dayanmaktadır. Böylece sıcaklığın etkisiyle düşen neme bağlı olarak orman yangınları adet ve alan olarak artmaktadır. Çalışmamız ise uzun dönemli değişimlerin şiddetli rüzgar ve kararsız hava halleri üzerine etkisini, buradan hareketle de orman yangınları ile ilişkisini açıklamaya çalışmaktadır.

Çalışmada orman yangınları ile güneş aktivitesindeki periyodik değişimler karşılaştırılarak bir ilişki olup olmadığ 1 analiz edilmiştir. Güneş leke döngüsü, güneş radyasyon değişiminin en belirgin göstergesidir. Çalışmamız sonucunda güneş leke döngüsü ile orman yangını sayısı ve yanan alan miktarı arasında güçlü bir bağıntı olduğu ortaya çıkmıştır. Bu bağıntı ile gelecek dönemlere ait güneş döngü tarihleri kullanılarak orman yangınları açısından "yüksek risk potansiyeli olan yıllar” önceden tahmin edilebilecektir.

Y1llık orman yangını sayısı ve yanan alan verileri Orman Genel Müdürlüğü, Orman Yangınları İle Mücadele Dairesi Başkanlığı veri tabanından alınmıştır (OGM 2017). Veri sağlığı açısından değerlendirmeler; hem 1937 yılından günümüze kadar tutulan verilerle, hem de verilerin daha güvenilir olduğu 1970 yılından günümüze kadar tutulan verilerle ayrı ayrı yapılmıştır.

Güneş termodinamik bir yıldız olduğundan enerjisi sabit değildir. Güneşin ürettiği ve doğal olarak dünyamıza ulaşan enerji, dönemsel olarak inişli çıkışlı bir yapıya sahiptir. Atmosferimizdeki tüm olaylar da işte bu iniş çıkıştan etkilenmektedir. Güneş radyasyonunun ortalama 11 yıllık döngüsü boyunca minimum ile başlayan radyasyon seviyesi, döngünün orta noktasına doğru maksimuma çıkıp döngü sonunda tekrar minimuma inmektedir. Bir döngü boyunca atmosferimize ulaşan enerji seviyesi de bu döngüye bağlı olarak artıp azalmaktadır. Döngünün minimum ve maksimum noktalarında yaşanan büyük ve ani enerji değişimlerinin atmosferimizde radikal değişimlere sebep olabileceği düşünülmektedir.

$\mathrm{Bu}$ çalışmamızda güneş radyasyon verisi olarak, son yıllarda popüler bir kullanıma sahip "Güneş Leke Sayıları" verisi alınmıştır. Güneş radyasyon değişimi, döngü süresi içinde leke sayısıyla doğru orantılıdır ve döngüdeki minimum ve maksimum noktalarına bağlı olarak artıp azalmaktadır.

Güneş döngüsü verilerinin değerlendirilmesine ihtiyaç olduğundan, 1937-2016 yılları arasındaki "Güneş Leke Sayıları" verileri SIDC veri tabanından (http://www.sidc.be/silso/datafiles) çekilerek analiz edilmiş ve grafik haline dönüştürülmüştür (Şekil 3).

Çalışmada öncelikle 1937-2016 yılları arasında çıkan orman yangını verileri ile aynı döneme ait güneş radyasyon değişim verileri karşılaştırılmıştır (Şekil 4-5). Daha sonra OGM veri kalitesinin 1970'li yıllara kadar düşük olma ihtimali dikkate alınarak, 1970-2016 yılları arasında çıkan orman yangını verileri ile güneș radyasyon verileri de karşılaştırılmıştır (Şekil 6-7). Bunun yanında 19552016 yıllarını kapsayan 6 güneş döngüsü dönemi için hem dönemsel toplam leke sayıları hem de bu döneme ait yanan alan miktarları karşılaştırılarak aralarındaki korelasyona bakılmıştır.

\section{Bulgular}

Güneş döngüsü verileri ile yıllık orman yangını istatistikleri (OGM 2017) karşılaştırıldığında; 19372016 yılları arasında güneş döngüsünün minimum ve maksimum noktalarına denk gelen yıllarda, 


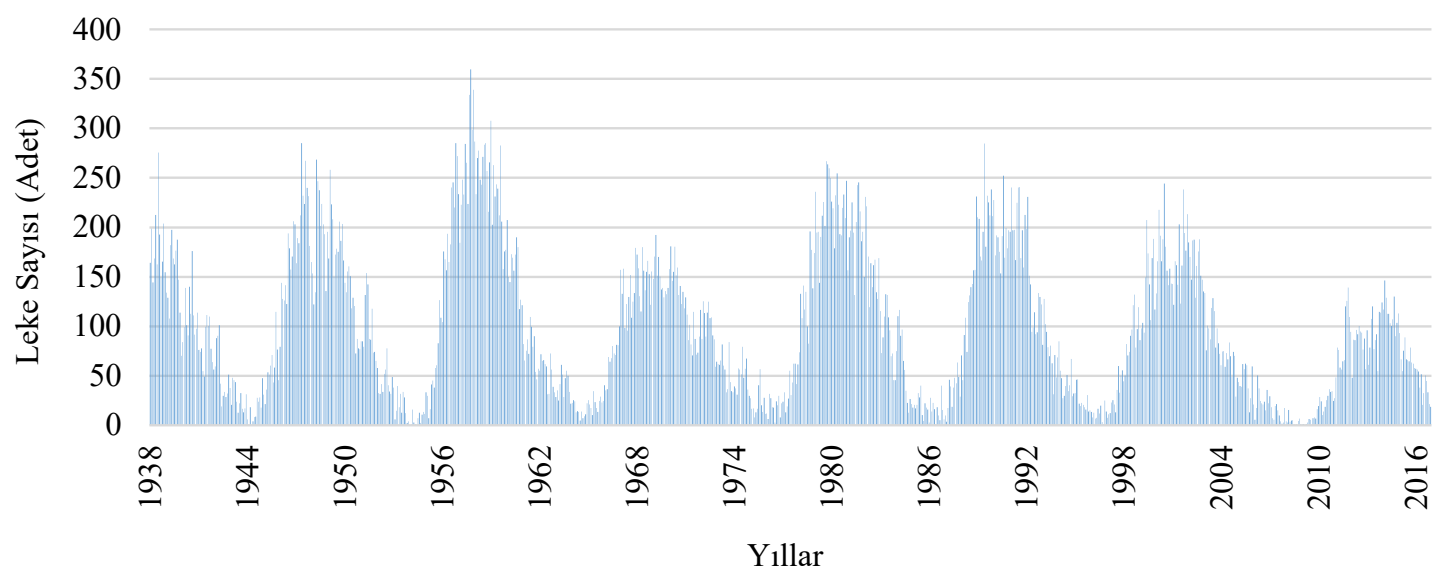

Şekil 3. 1937-2016 y1lları arasında Güneş Leke Döngüsü (http://www.sidc.be/silso/datafiles) Figure 3. Sunspot cycles between 1937-2016

diğer yıllara göre daha çok orman yangını çıktığ 1 (Şekil 4) ve daha fazla orman alanının yangından zarar gördüğü (Şekil 5) görülmektedir. Keza, OGM veri kalitesinin 1970'li yıllara kadar düşük olma ihtimali dikkate alınarak aynı karşılaştırma OGM'nin 1970-2016 yılları arası verileri ile tekrar edilmiş olup orman yangını verileri ve güneş radyasyon verileri arasında Şekil 6 ve Şekil 7'de görüldüğü üzere benzer bir ilişki tespit edilmiştir. Buna göre; orman yangınlarının en fazla sayıya ulaştığ 1 yıllar ile güneș döngüsünün minimum ve maksimum noktalarının yaşandı ̆̆ı yıllar birbiriyle çakışmaktadır

Güneş döngüsünün tüm minimum noktalarında mutlaka orman yangını açısından bir maksimum yıl yaşanmıştır. Ayrıca yangın adedi olarak en yüksek yıllar mutlaka güneş döngüsünün minimum ve maksimum noktalarına denk gelmektedir. Güneş döngüsünün minimum ve maksimum y1lları dışında kalan, grafiğin iniş ve çıkış yılları ise genel olarak orman yangınları açısından daha sakin geçen dönemler olarak tespit edilmiştir.

$\mathrm{Bu}$ bağıntılar; güneş döngüsünün minimum ve maksimum noktalarında dünyaya ulaşan enerji miktarındaki büyük değișimlerin kararsız hava hallerine yol açtığı, oluşan basınç farkları nedeniyle şiddetli rüzgarlar meydana geldiği ve bu durumun orman yangınları üzerinde büyük etkiler yaptığı şeklinde yorumlanabilir.

Dönemsel olarak yapılan karşılaştırmalar ise daha çarpıcıdır. Her döngü ortalama 10-12 yıllık dönemi kapsamaktadır. Bu zaman süresinde güneşte üretilen toplam enerji miktarı da dönemsel olarak değişmektedir. Yani her döngüde güneşten dünyaya ulaşan toplam enerji miktarları farklıdır. Toplam enerji bakımından döngüsel bazda güneş radyasyonu verileri ile aynı dönemde çıkan orman yanginlarından zarar gören toplam alan arasında belirgin bir doğrusal ilişki bulunmaktadır (Şekil 8).

Her döngünün minimum ve maksimum dönemlerinde orman yangınları açısından büyük artışlar görülmekle beraber, büyüklük olarak toplam enerjisi yüksek olan bir döngünün minimum ya da maksimum döneminde yanan alan miktarı, toplam enerjisi düşük olan döngüye göre çok daha yüksektir (Tablo-1).

Tablo 1. 1955-2016 y1lları arasında gerçekleşen güneş döngüleri boyunca oluşan toplam enerji ve bu dönemlerde yanan orman alanlar1 (http://www.sidc.be/silso/datafiles, OGM, 2017)

Table 1. The energy generated during the solar cycle between 1955-2016 and the burned areas during these periods

\begin{tabular}{ccc}
\hline $\begin{array}{c}\text { Dönem } \\
\text { (Yıllar) }\end{array}$ & $\begin{array}{c}\text { Toplam güneş radyasyonu } \\
\text { (Güneş Leke Sayıs1) }\end{array}$ & $\begin{array}{c}\text { Toplam yanan alan miktarı } \\
(\mathrm{Ha})\end{array}$ \\
\hline $1955-1964$ & 16.244 & 176.593 \\
$1965-1976$ & 12.061 & 126.839 \\
$1977-1986$ & 13.894 & 158.136 \\
$1987-1996$ & 12.644 & 152.229 \\
$1997-2009$ & 12.204 & 129.340 \\
$2010-2016$ & 6.083 & 44.332 \\
\hline
\end{tabular}




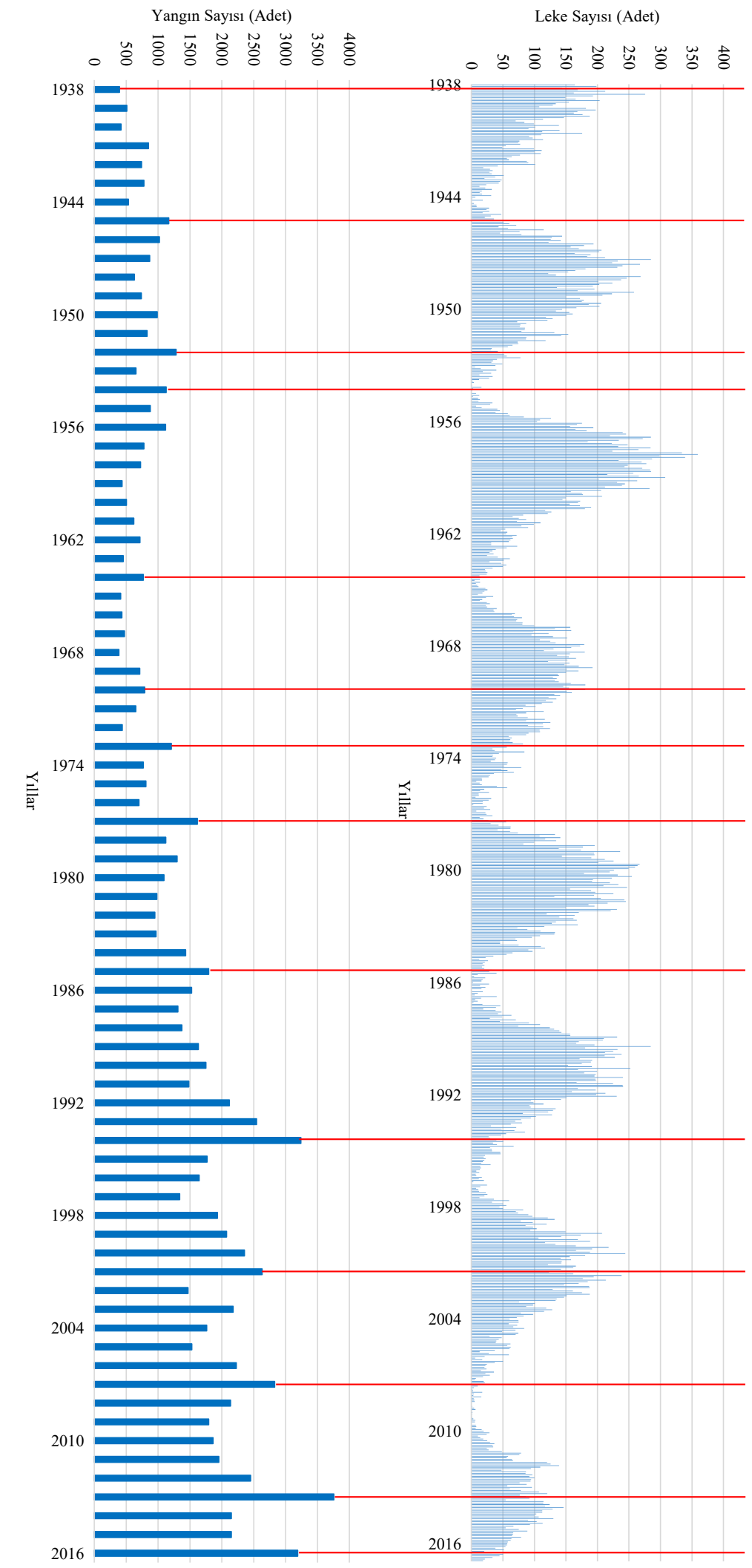

Şekil 4. 1937-2016 yılları arasında çıkan orman yangınlarının adet olarak güneş döngüsü verileri ile karşılaştırılması (http://www.sidc.be/silso/datafiles, OGM 2017)

Figure 4. Comparison between number of forest fires and solar cycle data between 1937-2016 


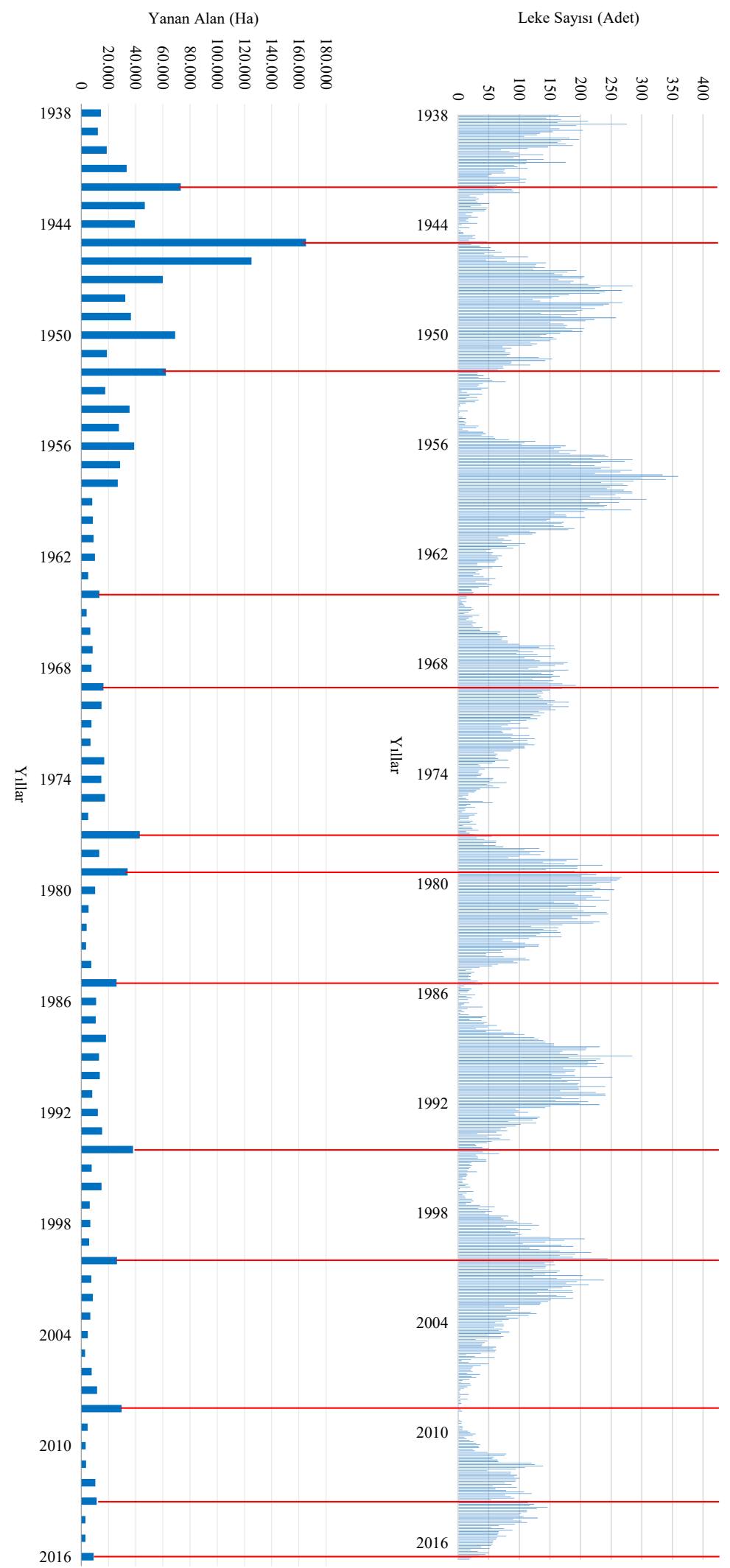

Şekil 5. 1937-2016 yılları arasında çıkan orman yangınlarının alan olarak güneş döngüsü verileri ile karşılaştırılması (http://www.sidc.be/silso/datafiles, OGM 2017:26)

Figure 5. Comparison between burned area and solar cycle datas between 1937-2016 


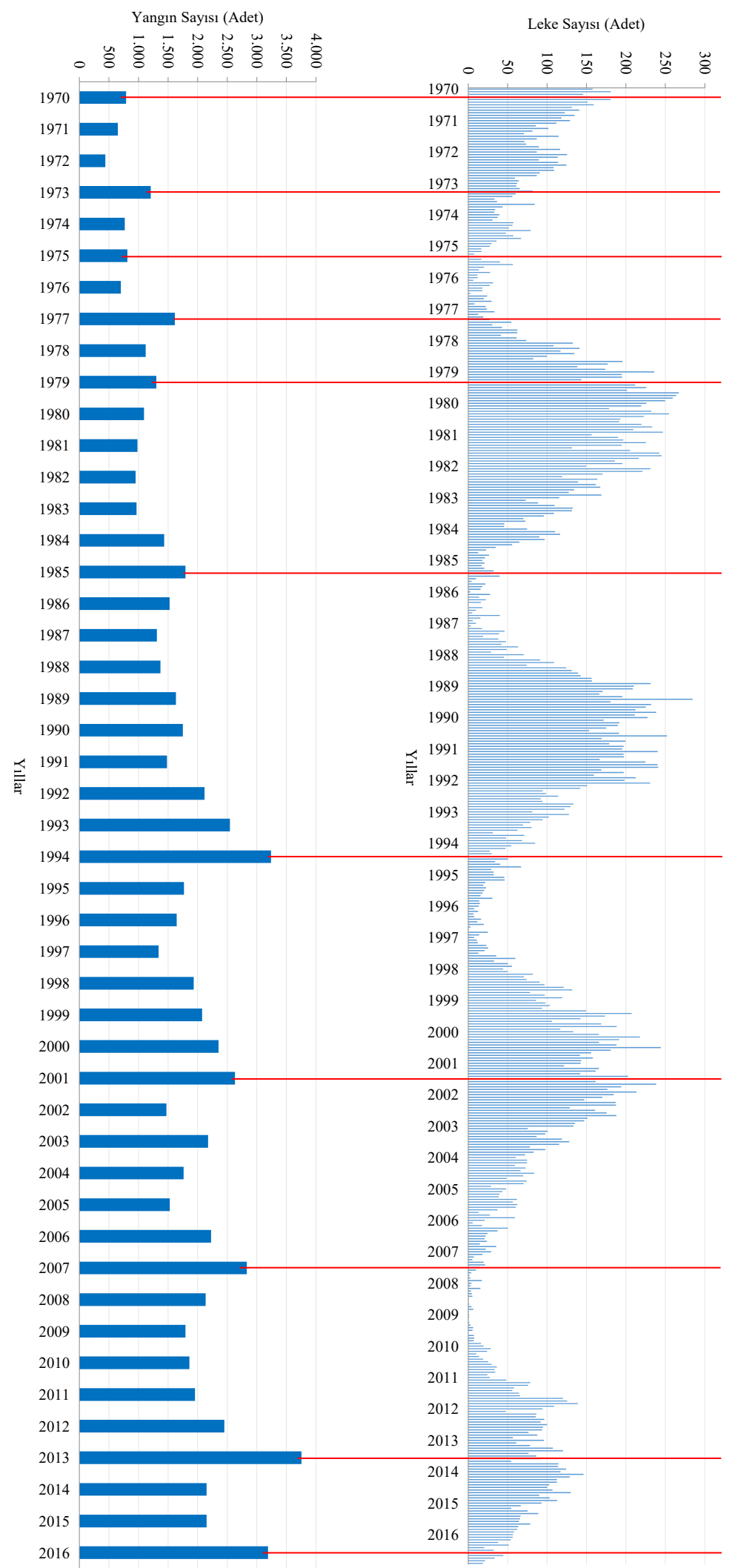

Şekil 6. 1970-2016 yılları arasında çıkan orman yangınlarının adet olarak güneş döngüsü verileri ile karşılaştırılması (http://www.sidc.be/silso/datafiles, OGM, 2017)

Figure 6. Comparison between number of forest fires and solar cycle data between 1970-2016 


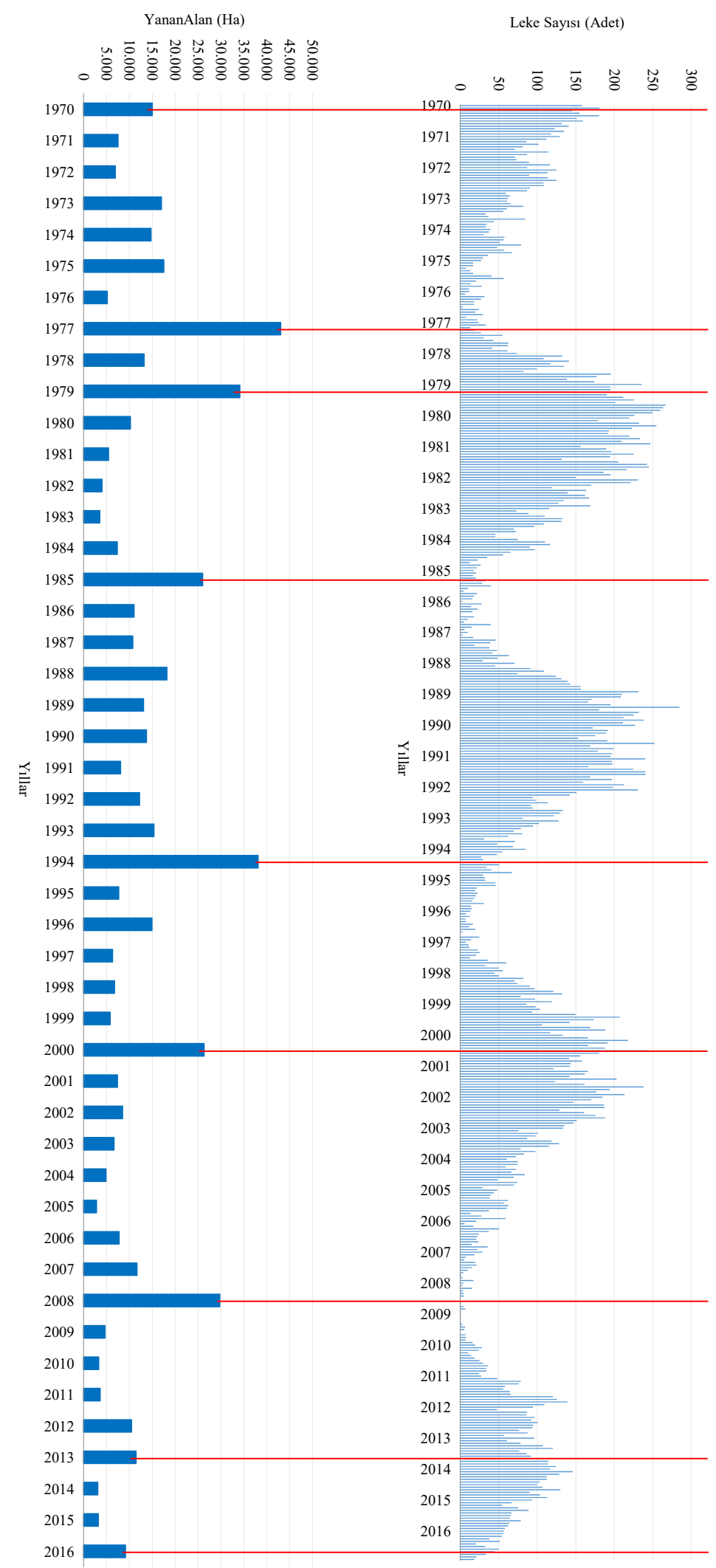

Şekil 7. 1970-2016 yılları arasında çıkan orman yangınlarının alan olarak güneş döngüsü verileri ile

Karşılaştırılması (http://www.sidc.be/silso/datafiles, OGM, 2017)

Figure 7. Comparison between burned area and solar cycle data between 1970-2016 


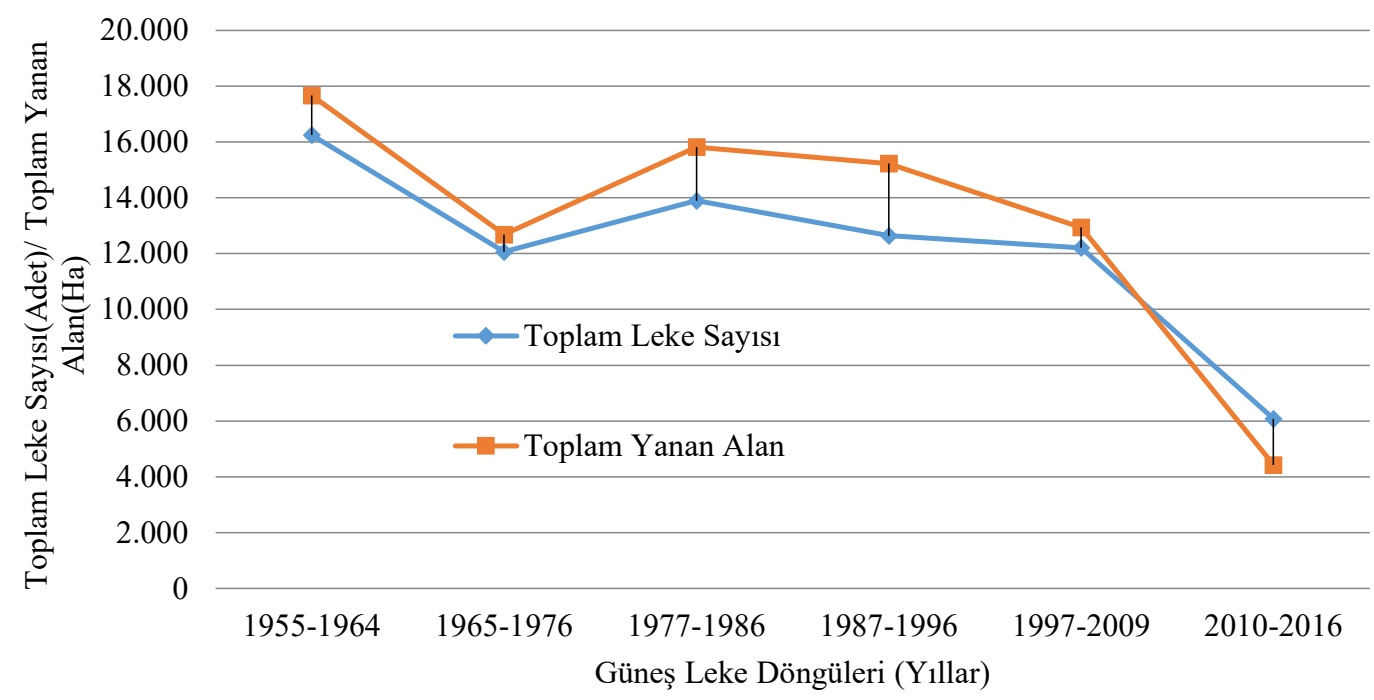

Şekil 8. "Dönemsel toplam güneş leke sayısı" ile "Güneş döngüsü” baz alınmış "Dönemsel toplam yanan orman alanı miktarı" ilişkisi (http://www.sidc.be/silso/datafiles,-OGM, 2017)

Figure 10. Relationship between Cyclic Total Number of Sunspots and Total Burned Forest Area Based on Solar Cycle

Döngü bazlı olarak hesaplanan toplam güneş radyasyonunu ifade eden güneş leke sayıları ile aynı dönem için hesaplanan toplam yanan orman alanı arasındaki korelasyon katsayısı ;

$$
\operatorname{Correl}(X, Y)=\frac{\sum(x-\bar{x})(y-\bar{y})}{\sqrt{\sum(x-\bar{x})^{2} \sum(y-\bar{y})^{2}}}
$$

$=+0,983$ olarak hesaplanmıştır.

Formülde, x: Toplam güneş radyasyonunu ifade eden dönemsel güneş leke sayıları (adet) serisini,

y: Aynı dönemler için hesaplanan toplam yanan orman alanı (Ha) serisini ifade etmektedir.

(PEARSON Korelasyon Metodunda, 0,80-1,00: arası değerler çok güçlü bağıntıyı ifade eder)

Yüksek enerjiye sahip döngüleri kapsayan yıllarda toplam olarak daha büyük orman alanları zarar görürken, düşük enerjiye sahip döngüleri kapsayan yıllarda ise daha küçük orman alanları zarar görmüştür. 2010-2016 yıllarını kapsayan döngü (Güneş Döngüsü-24) henüz tamamlanmamış olduğu için, 31 Aralık 2016 tarihine kadar üretilen toplam enerji ile aynı tarihe kadar çıkan toplam orman yangını verileri karşılaştırılmıştır.

\section{Tartışma ve Sonuç}

Dünyaya ulaşan enerjideki ani değişimler, özellikle güneş döngüsünün minimum ve maksimum noktalarında kararsız hava hallerine ve dolayısıy- la ani ve şiddetli rüzgarlara neden olabilmektedir. Büyük orman yangınlarının en önemli sürücüsü olan ani ve güçlü rüzgarlar, kararsız hava hallerinin yaşandığı dönemlerde büyük ve ani basınç farkları sebebiyle oluşmaktadır. Böylesine meteorolojik açıdan riskli zamanlarda çıkan orman yangınlarının, yanıcı maddenin sürekliliği de mevcut ise mücadele gücü ne olursa olsun kontrol altına alınabilmesi mümkün olmamaktadır. Kararsız koşullar nedeniyle süreç içerisinde birçok alçak ve yüksek basınç noktası oluştuğundan, orman yangını esnasında rüzgar yönünün ve dolayısıyla yangının ilerleme yönünün sürekli değişmesi de mümkün olabilmektedir. Böyle bir yangın ancak doğal bir engelle karşılaştığında yani önündeki yanıcı madde tükendiğinde kendiliğinden çökerek kontrol altına alınabilmektedir.

Bulgularımıza göre; güneş radyasyon değişimini temsilen kullanılan güneş leke döngüsü verileri, atmosferik kararsızlık dönemlerinin önceden tahmin edilebilmesine ve dolayısıyla orman yangınları açısından riskli yılların çok önceden tahminine olanak verebilir.

Çalışmanın sonuçları dikkate alındığında, döngünün minimum ve maksimum noktalarına denk gelen yıllarda orman yangınları için daha fazla tedbir alınması gerektiği açık bir gerçektir.

Bulgulara göre güneş radyasyonu "toplam enerji" bakımından da her dönem farklılıklar göstermiştir. Yüksek enerjili döngülerde çok daha büyük yangınların gerçekleştiği; düşük enerjili döngülerde 
ise yangın sayısının ve yangın büyüklüklerinin çok daha düşük olduğu tespit edilmiştir.

Bu durumda 10-12 yıllık dönemleri kapsayan güneş radyasyon döngüleri boyunca hangi dönemin orman yangınları açısından daha tehlikeli geçeceğini tespit etmek mümkündür. Orman yangınları ile mücadelede orta ve uzun vadeli programlar yapılırken bu tespitlerin göz önünde bulundurulması büyük önem arz edecektir. Özellikle bütçe planlamaları ve önceden alınacak tedbirler açısından bu öngörülerin dikkate alınması uygun olacaktır.

\section{Kaynaklar}

Aguado, I., Chuvieco, E., Martın, P. and Salas, J., 2002. Assessment of forest fire danger conditions in southern Spain from NOAA images and meteorological indices. International Journal of Remote Sensing, 24: 1664.

Bilgili, E., 2003. Stand development and fire behavior. Forest Ecology and Management, 179: 333-339.

Cramer, O.P., 2004. Recognizing weather conditions that affect forest fire behavior. Fire Management Today, V.64(1): 29-33.

Flannigan, M.D. and Wotton, B.M., 2001. Climate, weather and area burned In: Forest fires. New York Academic Press, NY pp. 351-373.

Gomes J.F., Radovanovic M., 2008. Solar activity as a possible cause of large forest fires-a case study: analysis of the Portuguese forest fires. Science of the Total Environment, 394(1):197-205

Küçük Ö., Bilgili E., Sağlam B., 2008. Estimating crown fuel loading for calabrian pine and Anatolian black pine. International Journal of Wildland Fire, 17:147-154.

Küçük Ö., Bilgili E., Sağlam B., Başkaya Ş., Dinçdurmaz B., 2007. Some Parameters Affecting Fire Behavior in Anatolian Black Pine Slash. Turkish Journal of Agriculture and Forestry 32(2): 121-129.

OGM (Orman Genel Müdürlüğü), 2017. Orman Yangınları Değerlendirme Raporu, S 26.

Rollo, T., 2004. Atmospheric stability forecast and fire control. Fire Management Today, 64(1):56-58

Saglam, B., Bilgili, E., Küçük, Ö., Durmaz, B.D., 2008. Fire behavior in Mediterranean shrub species (Maquis). African Journal of Biotechnology, 7 (22): 4122-4129

Sunspot Numbers | SILSO. (n.d.). Retrieved from http:// www.sidc.be/silso/datafiles (Erişim: 01.10.2017)

Zhou, X., Mahalingam S., Weise, D., 2007. Experimental study and large eddy simulation of effect of terrain slope on marginal burning in shrub fuel beds. Proceedings of the Combustion Institute, 31: 2547-2555.

https://www.nasa.gov/mission_pages/sunearth/ news/gallery/april2013-ssn_predict_l.html. Erişim : (01.10.2017) 